\title{
LOGICAL ASSESSMENT OF HOOKED END STEEL FIBRE REINFORCED CONCRETE IN M-40 GRADE FOR RIGID PAVEMENT
}

\author{
R. Kothadia ${ }^{1}$, C.B. Mishra ${ }^{2}$ \\ ${ }^{1}$ M.Tech Student, Transportation System Engineering, BVM Engineering College, V.V. Nagar, Anand, India \\ ${ }^{2}$ Associate Professor, Civil Engineering Department, BVM Engineering College, V.V. Nagar, Anand, India
}

\begin{abstract}
Road Infrastructure is an important driving force to achieve rapid and sustained economic growth in the changing technological innovation. A decent road system has an essential bearing on the monetary development of the nation. It is the obligation of roadway designer to keep concrete roads in activity commendable state by keeping pace with the fast extension and fortifying of the road arrangement yet they are experiencing issues to keep the roads in great condition. Consequently road development in our nation will be a ceaseless procedure, with concrete road reinforcing to be a real action for a long time to come. When rigid pavements are built, the mix design of concrete is focused around the compressive quality, which is utilized to guarantee that the target flexural quality as visualized in outline is attained to by and by, however exorbitant in beginning speculation, is modest in long run in light of low upkeep costs.
\end{abstract}

This paper deals with experimental investigation on mechanical properties of M40 grade concrete by incorporating hooked end steel fibres in dosages of 2\%, 2.5\% and 3.0\% by weight of cement into the mix. A comparative analysis has been carried out for conventional concrete to that of the hooked end steel fibre reinforced in relation to compressive and flexural strengths.

Keywords: Hooked end steel fibre, Concrete Mix Design, Compressive Strength, Flexural Strength. . $* * *$

\section{INTRODUCTION}

Road transportation is undoubtedly the lifeline of the nation and its improvement is an essential concern. Pavement fills two needs, in particular, to give an agreeable and tough surface for vehicles, and to lessen weights on hidden soils. The customary bituminous asphalts and their requirements for persistent support and restoration operations focus towards the extension for concrete solid asphalts. In India, owing to quick motors of development in framework and enormous climb in profoundly laden vehicles on restricted road space needs roads to withstand high burdens with least upkeep. Plain concrete pavements have low rigidity and strain limit, however these structural attributes are enhanced by fiber expansion, permitting diminishment of the asphalt layer thickness. This change can be noteworthy and relies on upon fiber qualities and measurement. The hugest impact of fiber support is to postpone and control the tensile cracking of composite material. Subsequently it is found to have huge effect on the pavement cost because of lessened thickness prerequisites, less support expenses and longer valuable life.

Steel fiber strengthened solid is cement made of concretes containing fine or fine and coarse total and hooked end steel strands. In strain, SFRC fizzles when the steel fiber breaks or is hauled out of the concrete grid. At first, physical properties of cement, aggregate and sand are completed in the research facility which must fulfill the necessity according to important IS codes. Correlation between the test on typical concrete blend and concrete blend with strands included measurements of $2 \%, 2.5 \% \& 3 \%$ substance by weight of concrete, to focus the compressive quality and flexural quality to accentuate the desperation to secure innovations, which is of most extreme imperative to the thruway engineers, road builders and pavement designers as well.

\section{OBJECTIVE OF PRESENT INVESTIGATION}

The reason for this study is to find effect of mixture in rate of hooked end steel fibre on properties of FRC i.e. workability, compressive quality, flexural quality for pavement construction.

\section{LITERATURE STUDY}

The hugest impact of the joining of steel fibres in cement is to postpone and control the tractable splitting of the composite material which absolutely impacts the mechanical properties of concrete. These enhanced properties bring about SFRC being a possible material for cement street asphalt. The studies carried out by Parviz [1] reasoned that cellulose filaments had measurably equivalent consequences for the plastic shrinkage breaking of conventional and high performance concrete. Soutsos [2] demonstrated that flexural sturdiness of concrete was found to increment impressively when steel and engineered fibres were utilized. Prahallada and Prakash [3] mulled over the impact of quality and workability qualities of waste plastic fiber fortified solid and found that the waste plastic filaments are extremely viable in controlling the cracks in concrete. Tests directed by Cengiz et.al [4] to study the impact of utilizing fly-ash remains, polypropylene strands, and steel fibres in concrete demonstrated that solid connection existed in the between 
abrasion and flexural rigidity, than between abrasion and compressive quality of the concrete containing either fly-ash or fibres or both. Ramadevi and Babu [5], the workability of cross breed fiber strengthened solid blend was expanded by expansion of a super plasticizer. The test a consequence of the examination demonstrates that utilization of Hybrid Fiber strengthened solid enhances flexural execution of the beam amid loading. Ethar Thanon Dawood and Mahiyuddin Ramli [12] directed studies on hybridization of diverse rates of steel strands and palm fibres and reported that the utilization of hybrid fibres in specimens increments eminently the durability and subsequently builds their flexural strength what's more unbending nature and upgrade the general exhibitions of concrete.

\section{MATERIAL USED}

Ordinary Portland cement of 53 grades was used in this experimentation confirming to I.S.-12269-1987 for casting of concrete cubes and beams. Fine aggregate was natural river sand confirming to Zone II of IS 383:1970 with maximum size of less than 4.75 having specific gravity 2.57 , water absorption $1.40 \%$ and fineness modulus 2.71 . The most important function of the fine aggregate is to assist in producing workability and uniformity in mixture. The fine aggregate also assists the cement paste to hold the coarse aggregate particles in suspension. The sieve analysis is conducted to determine the particle size distribution in a sample of aggregate, which we call gradation.

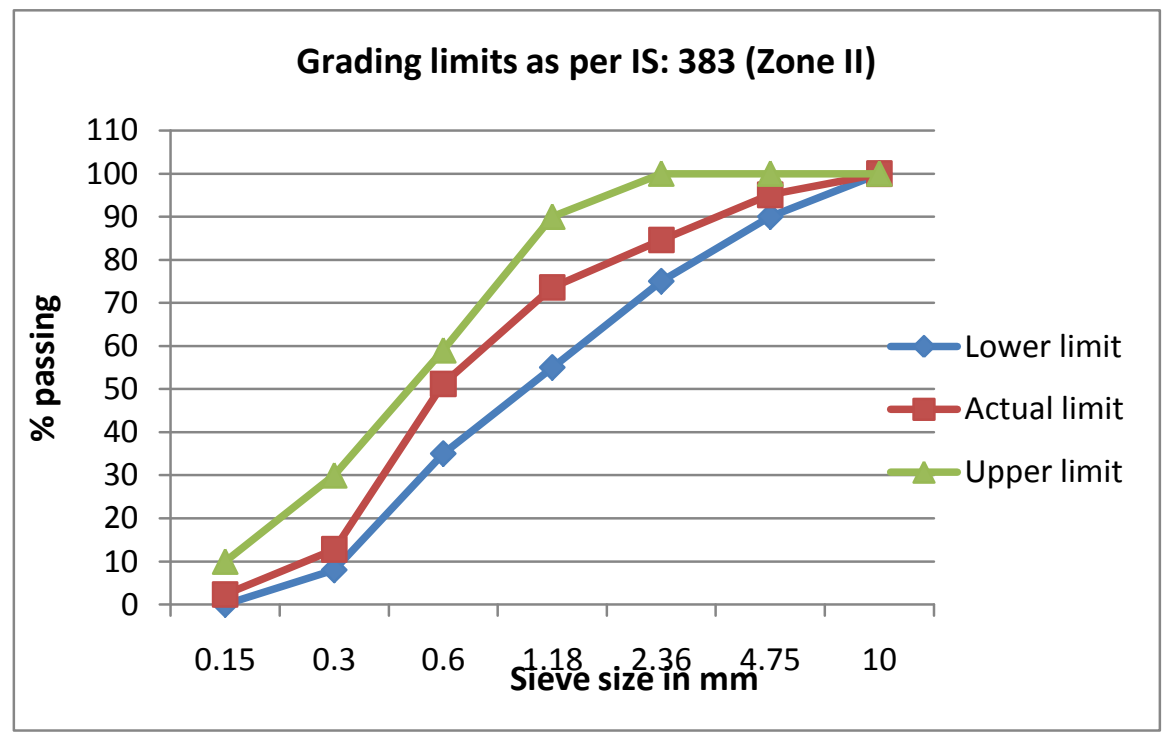

Chart -1: Sieve analysis of fine aggregate

Coarse aggregates of size $20 \mathrm{~mm}$ and $10 \mathrm{~mm}$ with particular gravity 2.94 and 2.83 and water retention $0.85 \%$ and $1.30 \%$ individually. The aggregate possess a critical volume of concrete and thus their impact on different properties of concrete is extensive. Properties of totals enormously influence the properties of concrete, for example, workability, quality, sturdiness and economy.

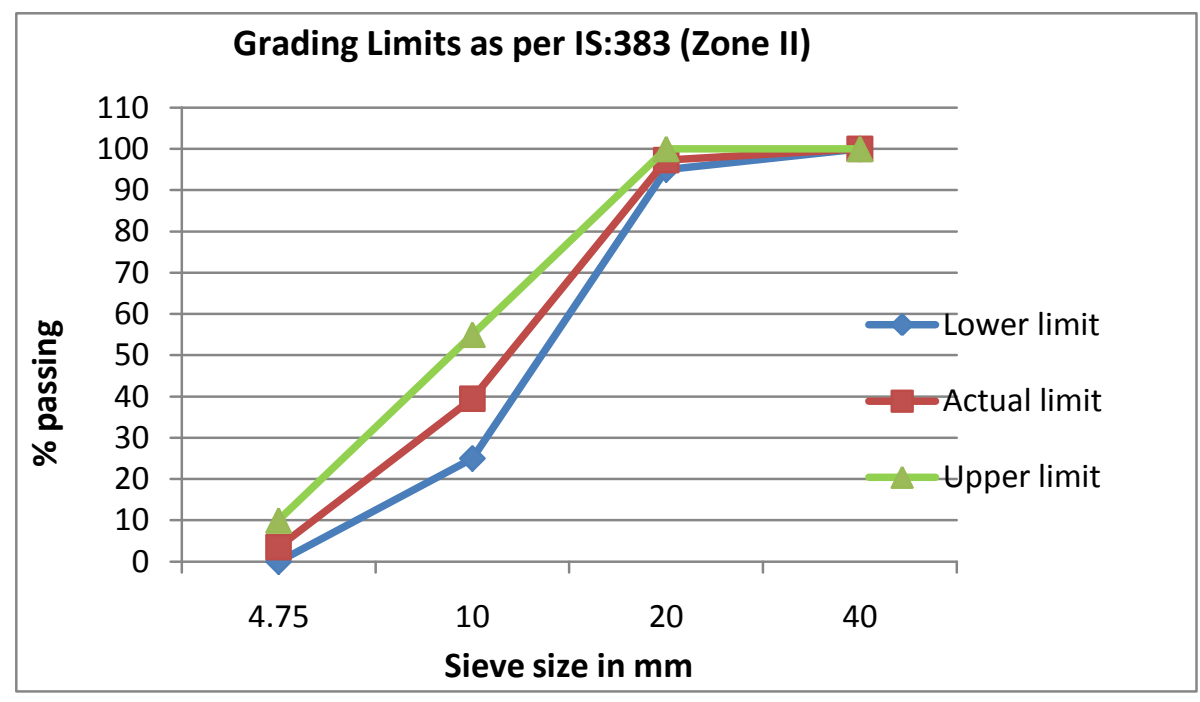

Chart -2: Combined Sieve analysis of coarse aggregate 
BASF Rheobuild 1126 - an additive is made out of engineered polymers extraordinarily intended to permit significant diminishment of blending water while keeping up control on reach out of set hindrance. It likewise has great scattering quality, high workability for more periods, imperviousness to isolation even at high workability, lessened water content for a given workability and expanded simplicity in completing concrete. It was included $1.0 \%$ by weight of cement in concrete. In this experimentation hooked end fibres were used of $30 \mathrm{~mm}$ length and $0.5 \mathrm{~mm}$ diameter with aspect ratio 60 . Fibres are having prevalent high temperature execution and better scattering giving simpler taking care of and enormously expanding the life of pavement. Portable water adequate for the concrete was utilized as a part of the study

\section{CONCRETE MIX DESIGN (As per I.S. 10262 - 2009)}

Table 1: Concrete Mix Design M-40 Grade

\begin{tabular}{|l|l|l|l|l|l|l|}
\hline Index & $\begin{array}{l}\text { Cement } \\
\mathrm{kg} / \mathrm{m}^{3}\end{array}$ & $\begin{array}{l}\text { C.A. } \\
20 \mathrm{~mm} \\
\mathrm{~kg} / \mathrm{m}^{3}\end{array}$ & $\begin{array}{l}\text { C.A. } \\
10 \mathrm{~mm} \\
\mathrm{~kg} / \mathrm{m}^{3}\end{array}$ & $\begin{array}{l}\text { River } \\
\text { Sand } \\
\mathrm{kg} / \mathrm{m}^{3}\end{array}$ & $\begin{array}{l}\text { Additive (\% } \\
\text { by wt of } \\
\text { cement) }\end{array}$ & Water \\
\hline PC & 410 & 764 & 490 & 742 & $1 \%$ & 148 litres \\
\hline
\end{tabular}

\section{EXPREMENTAL RESULTS}

Slump Test: The workability of fresh concrete mixes were determined by slump test for attaining the consistency and uniformity of mix as per criteria's laid down in MoRTH Table 1700-4. The hooked end steel fibres in suitable dosages of 2\%, $2.5 \%$ and 3\% are added to the fresh concrete. The bleeding of concrete mixes was judged visually. The slump values obtained is as shown in the table.

Table 2: Slump test values

\begin{tabular}{|l|l|l|l|l|}
\hline & Normal concrete & $\begin{array}{l}\text { SFRC with 2\% } \\
\text { fibre content }\end{array}$ & $\begin{array}{l}\text { SFRC with 2.5\% } \\
\text { fibre content }\end{array}$ & $\begin{array}{l}\text { SFRC with 3\% } \\
\text { fibre content }\end{array}$ \\
\hline Initial & Collapse & Collapse & Collapse & Collapse \\
\hline After 30 min & 200 & 195 & 185 & 180 \\
\hline After 60 min & 170 & 160 & 155 & 150 \\
\hline After 90 min & 150 & 150 & 140 & 135 \\
\hline
\end{tabular}

Required 100-200 mm (MoRTH Table 1700-4)

It is obvious from the table that as the rate of fiber substance builds slump qualities are diminishing. The lessening in the droop with the increment in the fiber will be credited to vicinity of fibres which causes obstacle to the free flow of concrete. The slump test is time respected custom in concrete engineering for knowing the consistency and consistency of mix as it is reliant on total dampness substance, concrete temperature and blending.

Compressive Strength Test: For compressive quality test, solid shape examples of measurements 150 x 150 x $150 \mathrm{~mm}$ were thrown for M-40 evaluation of cement. Super plasticizer (1.0\% by weight of cement) was added to this. Fibres were added to concrete amid blending period in extent of $2 \%, 2.5 \%$ and $3 \%$ by weight of cement. Vibration was given to the molds utilizing table vibrator. The top surface of the sample was leveled and completed. Following 24 hours the samples were demoulded and were exchanged to curing tank where in they were permitted to cure. Following 3 days, 7 days, and 28 days curing, these cubes were tested on digital compression testing machine as per I.S. 516-1959. The failure load was noted. In every classification three cubes were tried and their average quality is accounted for. The graph demonstrates the variety of compressive quality to $\%$ of fibres and it is watched that the compressive quality of concrete is expanding with the increment in fiber substance contrasted with customary solid at 3,7 and 28 days 


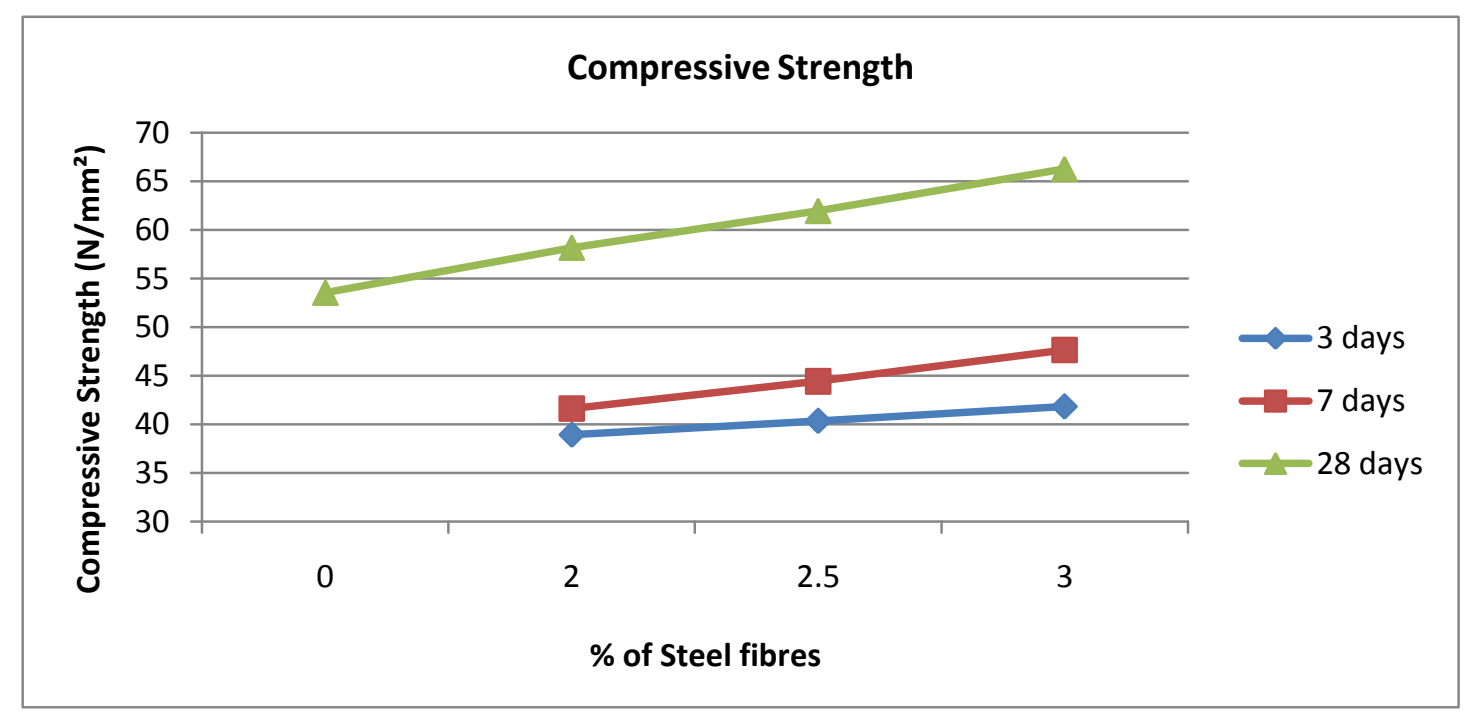

Chart -3: Variation of Compressive Strength with respect to \% of fibres

Flexural Strength Test: For flexural quality test specimens of measurement 100x100x500 mm were casted. The specimens were casted with and without fibres. The samples were demoulded following 24 hours of casting and were exchanged to curing tank where in they were permitted to cure for 28 days. These flexural quality specimens were tried under two point loading according to I.S. 516-1959, over a compelling span of $400 \mathrm{~mm}$ on flexural testing machine. Load and comparing corresponding deflections were noted up to failure. In every category three beams were tested and their average worth is accounted for as shown in the graph

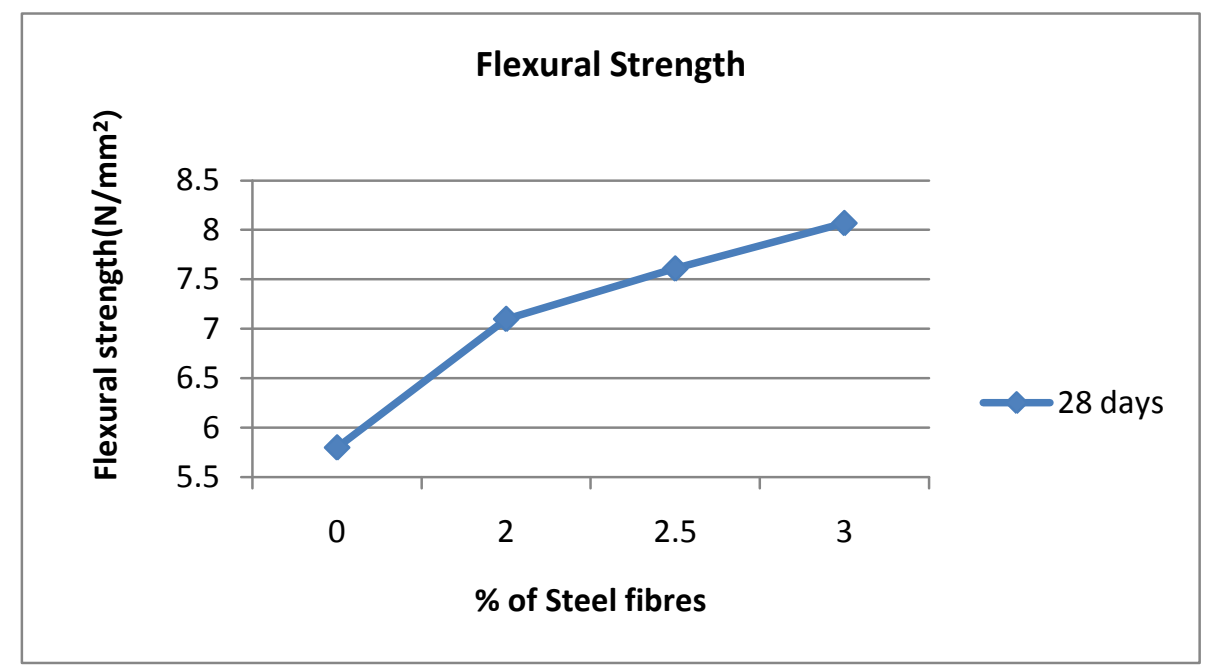

Chart -4: Variation of Flexural Strength with respect to \% of fibres

\section{CONCLUSION}

Flexural quality can be utilized for configuration purposes, however the comparing compressive quality used to request and acknowledge the concrete is must. This study has been made to focus the impact of hooked end steel fibres in suitable measurements on quality of concrete. The significant conclusions that rose up out of the exploratory examinations are focused as beneath:

1. It is evident that as the rate of hooked end fibres increases, the slump qualities are decreasing. The diminishing in the hang with the addition in the fiber will be credited to region of fibres which causes hindrance to the free stream of concrete. Super plasticizer used in concrete keeps the mix in workability condition even with increasing time within permissible limits of codal provision.
2. It is watched that compressive quality and flexural quality are on higher side for 3\%, fibre content as contrasted with that delivered from $2 \%$ and $2.5 \%$. This signifies that the impact of fibre is evident on increasing quantity.

3. It is observed that compressive strength increases from $8 \%$ to $26 \%$ with addition of hooked end steel fibres which is considerable enough.

4. It is observed that flexural strength increases drastically with the increase in fiber content compared to conventional concrete from $19 \%$ to $41 \%$. Fibre not only increases the flexural strength but also post cracking ductility of concrete is increased. Fibres may be used to improve the toughness of concrete also and also improves the impact strength and inherent flexural strength. 
Looking to the study one can say that usage of hooked end steel fibres opens a new hope to developing and globalizing the quality and reshaping the face of the "True Indian Roads".

\section{REFERENCES}

[1]. Parviz soroushian \& Siavosh Ravanbakhsh,"Control of plastic cracking with specialty cellulose fiber", ACI Materials Journal, V.95, No.4 (2012), page 429-435.

[2]. M.N. Soutsos, T.T. Le, A.P. Lampropoulos," Flexural performance of fibre reinforced concrete made with steel and synthetic fibres", Construction and Building Materials 36 (2012) 704-710.

[3]. M.C, Prahallada and K.B, Prakash (2011) Strength and Workability Characteristics of Waste Plastic Fibre Reinforced Concrete Produced From Recycled Aggregates. International Journal of Engineering Research and, 1 (4). pp. 1791-1802. ISSN 2248-9622.

[4]. Cengiz Duran Atis and Okan Karahan.,(2009) "Relation Between Strength Properties (Flexural And Compressive) And Abrasion Resistance Of Fiber (Steel And Polypropylene) Reinforced Fly-ash concrete", ASCE , Journal Of Materials In Civil Engineering, Vol.21, Issue-8, pp 402-408.

[5]. Ramadevi K., Venkatesh Babu D. L. (2012), "Flexural Behaviour of Hybrid (Steel-Polypropylene) Fibre Reinforced Concrete Beams", European Journal of Scientific Research, ISSN 1450-216X Vol.70 No.1, pp. 8187.

[6]. Eethar Thanon Dawood and Mahyuddin Ramli (2011) "Contribution of Hybrid Fibers on The Hybrid Fibers on the Properties of High Strength Concrete Having High Workability" proceedings of Twelfth East Asia-Pacific Conference on Structural Engineering and Construction. Procedia Engineering 14 (2011) 814-820.

[7]. IS: 2386 (part-1)-1963, "Methods of testing for aggregate for concrete".

[8]. IS: 10262-2009, "Recommended guidelines for concrete mix design, Bureau of Indian standards", New Delhi, India.

[9]. IS: 516-1959, Indian standard methods of tests for strength of concrete, Bureau of Indian Standards, New Delhi, India.

[10]. IRC: 44-1976, Tentative guidelines for cement concrete mix design for pavements.

[11]. IS 383:1970, Specification for Coarse and Fine aggregates from natural sources for concrete

[12]. I.S.-12269-1987, Specification for 53 grade ordinary portland cement

\section{BIOGRAPHIES}

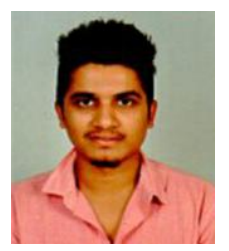

Smit R. Kothadia is a student obtained B.Tech (Civil) from Charusat University, Changa. Currently pursuing M.Tech Sem III (TSE) from B.V.M. Engineering College, V.V. Nagar

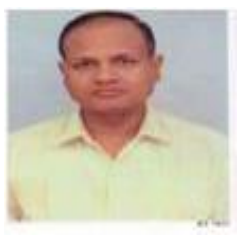

Prof C. B. Mishra is M. E Civil specialized in Highway Engineering possess about 29.3 years of teaching experience in B.V.M. Engineering College, V.V. Nagar. He has published 25 papers to his credit, organized 10 short term training programs and also conducted 9 seminars at the national levels. He was elected as one of the committee member of ISTE Gujarat section. Currently he is guiding M.Tech students in their dissertation work in B.V.M Engineering College 